\title{
Blade Runner depois dele mesmo: ambiguidade e fotogenia no pós-humano
}

\author{
Blade Runner after himself: \\ ambiguity and photogenic in the post-human
}

\begin{abstract}
Eduardo Portanova Barros I eduardoportanova@hotmail.com Possui graduação em Comunicação Social pela Pontifícia Universidade Católica do Rio Grande do Sul (1986), mestrado em Ciências da Comunicação pela Escola de Comunicações e Artes da Universidade de São Paulo (2003) e doutorado em Comunicação Social pela Pontifícia Universidade Católica do Rio Grande do Sul (2009). Habilitação em Jornalismo (Impresso, Radiofônico, Televisionado e Cinematográfico). Atua como jornalista e professor. Pesquisa assuntos na área da Comunicação, das Ciências Sociais, do imaginário e dos meios audiovisuais. Pesquisador do Imaginalis - Grupo de Estudos sobre Comunicação e Imaginário (cadastrado junto ao (NPq). É parecerista ad hoc. Traduziu artigos de Armand Mattelart, Lucien Sfez e Pierre Lévy, entre outros, e o livro "Sociologia do imaginário", de Patrick Legros, Frédéric Monneyron, Jean-

Bruno Renard e Patrick Tacussel (Porto Alegre: Sulina, 2007).

Carlos Alfredo Gadea Castro I cgadea@unisinos.br Pós-doutorado na University of Miami (USA). Doutor em Sociologia Política pela Universidade Federal de Santa Catarina (2004). Realizou estudos e pesquisas doutorais no Ibero-Amerikanischen Institutes Berlin - IAI (Alemanha) e na Facultad de Ciencias Políticas y Sociales da Universidad

Nacional Autónoma de México - UNAM (México). Possui Mestrado em Sociologia Política pela

Universidade Federal de Santa Catarina (1999) e é egresado do Instituto de Professores Artigas

(1996, Uruguai) como Professor de História. Recebeu o Prêmio SOBER (Sociedade Brasileira de Economia e Sociologia Rural) como melhor dissertação de mestrado em Sociologia (Rio de Janeiro,

2000) e o Prêmio TEMAS de Ensaio 2001 (Havana, Cuba). Atualmente é Professor Titular do Programa de Pós-graduação em Ciências Sociais na Universidade do Vale do Rio dos Sinos e Editor da Revista Ciências Sociais Unisinos.
\end{abstract}

\footnotetext{
Resumo

E ste artigo discute a questão da ambiguidade, através da fotogenia, em Blade Runner, filme dirigido por Ridley Scott e que é baseado no livro "O caçador de andróides" (Do androids dream of electric sheeps?), de Philip Kindred Dick. A escolha deste filme se justifica pelo fato de que os androides adquirem, em muitas situaçôes, comportamentos humanos.
}

Palavras-Chave: Cinema; Fotogenia; Ambiguidade.

\begin{abstract}
This article discusses the issue of ambiguity in Blade Runner in terms of photography. The film is directed by Ridley Scott and is based on a book from american writer Philip Kindred Dick, "Do androids dream of electric sheeps?" (New York: Ballantine Books, 1968). The choice of this film is justified by the fact that the androids acquire, in many situations, human behavior.
\end{abstract}

Keywords: Cinema; Photogenic; Ambiguity. 
O caráter fotográfico de um filme não se restringe ao enquadramento figurativo. Um filme, sob o ponto de vista da direção de fotografia, pode ser antes o resultado de uma atmosfera da imagem, por via, paradoxalmente, desse artefato técnico que é a câmera, do que a visibilidade dos elementos retratados. E essa atmosfera da imagem poderia ser definida, simplesmente, como fotogenia, caracterizada por Morin (1997) por três noçóes: o aspecto poético, o potencial emocionante e a qualidade moral. Assim, o que nos daria a sensação de ambiguidade da questão identitária dos personagens em Blade Runner é a fotogenia, algo além da simples forma, mas não a fotografia. E se a fotografia do filme tem um caráter fotogênico neste filme, a leitura que nós espectadores fazemos se volta para um aspecto libertário, sem uma preocupação formal tão grande. Vejamos, portanto, como a fotogenia de Blade Runner definiria a ambiguidade do pós-humano no filme. Quem somos nós?

Poderíamos pensar com Maffesoli (1995) que somos, hoje, um produto (palavra um tanto inapropriada para designar o humano ser) das identificaçôes. Não que a identidade deixe de existir, mas o ser que se relaciona com o Outro busca, antes, coisas em comum, e não só a diferenciação identitária. Para Maffesoli (1995), estamos passando de uma lógica da identidade para a da identificação. Nosso interesse está relacionado ao momento, ao presente e à estetização da vida. Nosso cotidiano é menos contratual, menos identitário e menos ideológico. Esses valores, segundo Maffesoli, prevaleceram na modernidade. Hoje, porém, no que ele chama de pós-modernidade, período em que o sensível aflora em meio à tecnologia de ponta, as coisas adquirem novos valores. Só nos reconhecemos no outro, como uma irmandade. "Ao indivíduo, oposto à pessoa, corresponderia a identidade, oposta à identificação" (MAFFESOLI, 1995, p. 309). Para ele, a supremacia do individualismo não é um valor único e atemporal.

Poderíamos fazer uma analogia dessa tese maffesoliana com Blade Runner ${ }^{1}$, de Ridley Scott, filme no qual a identidade parece ambígua, por causa, justamente, desse aspecto paradoxal evidenciado pela identificação. Os replicantes são seres humanos ou máquinas? Com quem eles se identificam mais? Veremos que, no filme, alguns traços na personalidade deles se diferenciam dos humanos. A replicante Rachel (Sean Young), por exemplo, se apaixona por Deckard (Harrison Ford). Mas como isso é possível se os replicantes, aparentemente, não têm sentimentos e estão programados para morrer em quatro anos? Qual é a fronteira entre a humanidade e a máquina? A surpresa de nos vermos menos humanos do que suporíamos é um elemento para uma das possíveis leituras do filme.

Os limites entre a humanidade e o mundo artificial se tornam pouco claros na história: um androide ou replicante pode mostrar-se mais humano do que o próprio humano, ou, pelo menos, mais racional e capacitado para lidar com seus desejos e sentimentos, e, por consequência, mais complexo. $\mathrm{O}$ filme Blade Runner é sobre o ato de olhar e sobre a representação do olhar. $\mathrm{O}$ órgão da visão, o olho, é uma constante. Nessa representação do olhar, a água que está na chuva e a transparência que está no vidro se misturam às luzes 
flutuantes e às sombras que parecem esconder o caos e a irrealidade que governam a cidade de Los Angeles em 2019. Nas ruas, um caos em movimento. Estes aspectos são salientados na fotografia deste que é considerado um filme "noir" (isto é, com características semelhantes aos filmes policiais dos anos 50, nos Estados Unidos, que mostravam, geralmente, uma atmosfera sombria com tonalidades escuras e pouco contrastadas).

Nos edifícios, o símbolo da ruína e o isolamento, a solidão e o frio. Em Blade Runner, aliás, os humanos estão todos sós, mas os replicantes não. As transparências, como no vestido de Zhora (dançarina com a cobra), a importância do olho que simboliza o ato de olhar e o império do visual (inclusive para distinguir os mundos humano e artificial) parecem condensar-se numa temática sobre o tempo e a memória. Por exemplo, quando Batty diz para Chew: "se tão só conseguisse ver o que eu tenho visto com teus olhos". Ou: "eu tenho visto coisas que você não poderia crer. Naves de ataque em chamas, além do Órion. Tenho visto raios $\mathrm{C}$ brilharem na escuridão perto da porta de Tanhauser. Todos esses momentos se perderam no tempo como lágrimas na chuva. Tempo de morrer".

Na paranoia do filme, o tempo e a memória procuram encontrar o segredo da vida, o tempo perdido, como nas fotografias: elementos recorrentes que sugerem a existência de uma prova de uma vida anterior que comprove um passado "humano" e um presente também humano. É o desespero de Rachel. Mas Blade Runner sugere como eixo central "brincar" com as dualidades, com os binarismos, com as distinçôes entre certo/errado, natureza/cultura, natureza/artifício, natureza/máquina. Dualidades que se quebram como, por exemplo, na suspeita da relação de amor entre Deckard e Rachel. Apaixonar-se "de" e "por" uma máquina seria possível? A máquina, o replicante, parece mais humana do que os próprios humanos. E não poderia ser assim? Isto é: a máquina não poderia ser definida como algo mais humano que o próprio humano?

Não se condensa na máquina (ou na técnica) a expressão mais lúcida do espírito humano? Heidegger pensa na técnica como essência. Não está na máquina a projeção do humano, os seus desejos e ambiçôes? Não há uma relação de amor nesse gesto de dar vida? Blade Runner apresenta a perseguição de um sistema totalitário em que o ato de matar significa um ato de aposentar, tirar de circulação, deixar inativo. Os humanos se apresentam ferozes e selvagens - com exceção, talvez, de Deckard, que parece desconcertado em meio a tanta brutalidade, apesar de se concentrar em cumprir a tarefa para a qual fora designado enquanto os replicantes são complexos, ansiosos, esperançosos, contraditórios, humanos. Rachel é a imagem do medo, do amor e da confusão por trás de seus movimentos lentos e do rosto de porcelana. Também é considerada uma androide especial, porque fazia parte de algumas experiências em andamento da corporação que criava esses androides.

Rachel tinha certeza das suas lembranças e da sua identidade até que se descobriu vulnerável tal qual uma humana, mas ainda máquina. E que máquina é essa para a qual um gesto amoroso faz algum sentido? Não seria o caso de nos perguntarmos quem, afinal de contas, é androide nesse filme? 
Batty, a máquina, mostra a sua face humana ao salvar a vida de Deckard, o humano, como se nesse gesto de não deixá-lo morrer estivesse a sua própria continuidade como um ser vivo. A partir desse momento, entendeu que poderia viver através de Deckard. Deckard, por sua vez, é um ser marginal. Abandonou seu trabalho e, agora, tornou-se um ex-assassino de replicantes. É como um Batman, só que mais vacilante e precário na sua sensibilidade. Pris é como uma órfấ pós-feminista: consumidora de mais vida; brincalhona; ingênua. $\mathrm{O}$ final do filme nos leva ao início.

Aquele início da dúvida de identidades entre ser um humano ou um replicante. Batty está se tornando mais humano, pois chora a morte de Pris e seu próprio fim, depois de salvar Deckard, um gesto que o policial talvez náo tivesse - por estar "embalado" em eliminar o rebelde replicante. Deckard reflete, confusamente: "não sei por que ele salvou minha vida. Talvez, naqueles momentos finais, ele amou a vida mais do que nunca. Não apenas a vida dele. A vida de qualquer um. Minha vida. Tudo o que ele queria eram as mesmas respostas que o resto de nós quer. De onde eu venho? Para onde eu vou? Quanto tempo tenho? Tudo que eu podia fazer era sentar ali e vê-lo morrer". Provavelmente, com a morte do replicante Batty, ele descobriu a sua definitiva humanidade, a sua finitude.

Talvez com a sobrevivência do humano, Deckard comece a suspeitar da sua natureza replicante, mecânica, sem perder-se, claro, a ideia de que esta dualidade homem-máquina seja tão só uma arbitrária e sombria construção da realidade, como a que está presente em Blade Runner. Para Heidegger, o que está em jogo não é a tecnologia, e sim a essência da técnica, como se disse antes. Nós, humanos, estamos investidos de técnica, sem sabermos exatamente a finalidade dela. Nessa errância pós-moderna, vivemos um problema metafísico, sem resolução. "a técnica é uma forma de des-encobrimento”, afirma Heidegger (2008, p. 17). Des-encobrir é o mesmo que desnudar. Estamos desnudos de sentido na pós-modernidade. A mesma nudez com que se viu Baudelaire no século XIX com a perda do halo ou Walter Benjamin com a perda da aura na época da reprodutibilidade técnica.

Ora, o mesmo se passa em Blade Runner. O des-encobrimento em Heidegger, a perda do halo em Baudelaire ou a da aura em Benjamin é a tomada de consciência de outra realidade. Rachel perde o halo de androide ao se apaixonar por Deckard (um humano) e vice-versa. Já não é possível ver as coisas com clareza, e, se não há clareza, não há distinção. Em não havendo distinção, se instala a ambiguidade. Heidegger irá tratar a técnica da mesma forma, como sendo algo ambíguo, ao mesmo tempo humana (não esqueçamos que é uma criação do homem) e espiritual (não esqueçamos o componente transcendental com que o homem reveste suas açóes). Assim, seria algum exagero afirmarmos que a técnica é uma questão transcendental?

\section{O imaginário tecnológico}

Podíamos remeter a temática homem-máquina aos estudos do imaginário em Gilbert Durand. Não se trata aqui de uma mitocrítica, método criado 
pelo próprio Durand para ver a recorrência (ou metáforas obsessivas) de alguma situação nas cenas do filme, por exemplo, e, sim, de uma leitura de cunho fenomenológico. A questão do imaginário de que falamos é a de uma troca, incessante, entre a subjetividade e as intimaçôes do meio em que vivemos. É o que Durand denomina "trajeto antropológico". E Blade Runner, sob esse aspecto, é bastante fecundo. O problema, desde o início, seja na versão para o cinema, seja na versão final do diretor (Final cut), é a permanente dúvida entre o ser máquina e a máquina ser. Para Wunenburger, a Teoria Geral do Imaginário de Gilbert Durand apresenta esse imaginário como "uma organização complexa e sistêmica de imagens" (2007, p. 36). O termo imagem nos remete tanto ao iconicismo dele quanto ao sentido figurado.

Teórico de uma sociologia do imaginário, Maffesoli considera a "socialidade pós-moderna transfigurada pelas imagens” (1995, p. 135). Este paradoxo, a da imagem objeto e a da imagem mental, é evidenciado pelo sociólogo francês quando ele observa que "não há nenhum aspecto da vida social que não esteja contaminado pela imagem” (Ibid., p. 137). Poderíamos acrescentar: seja qual for. A dialética entre o ser e o estar, que é a nossa condição de existência, só faz sentido através de uma imagem do que eu sou, do que eu sinto e do que eu vejo. A resposta para esses anseios aparece sob diversas facetas, comumente a do aspecto trágico da existência. Existência trágica porque, queiramos ou não, estamos ou caminhamos para um abismo - o abismo da insolubilidade do perecimento. Somos finitos, somos mortais. Enquanto náo conseguirmos superar, mentalmente falando, a morte que se aproxima, seremos existencialistas, da mesma forma com que Deckard e Rachel se veem.

Blade Runner é, assim como o imaginário, um filme complexo. Isto porque não procura dar todas as respostas, mesmo tendo uma característica afetual comum nos filmes de ação contemporâneos, e também porque, tomando a complexidade no sentido de Morin, procura antes manter as contradiçôes possíveis do que eliminá-las dialeticamente, quando se pensa que A sendo diferente de $B$, então $C$ seria outra coisa que nem A e nem B. A estrutura de Blade Runner é linear, no sentido de ter, claramente, um início, um meio e um fim. Repetimos: mesmo que o final seja "aberto", na versão do diretor, ao contrário do final idílico (quando Deckard e Rachel sobrevoam, num dia ensolarado, algumas montanhas e desaparecem como se fossem, dali em diante, viver felizes para sempre), o esquema vogleriano da "jornada do herói” se impõe. Esse esquema, porém, não prejudica, necessariamente, o aspecto fotogênico ou autoral do filme. Vejamos o que diz Vogler.

Vogler é um executivo dos estúdios de Hollywood que adaptou o mito do herói, conforme os trabalhos de Joseph Campbell, para o cinema. E fez mais do que isso: escreveu um manual de roteiro que, logo depois, se tornou uma febre em Hollywood. Mais tarde, o manual se transformou no livro "A jornada do escritor. Estruturas míticas para contadores de histórias e roteiristas". Ele é baseado em "O heroi de mil faces", de Campbell, e trata da relação entre o mito e a narrativa moderna nos filmes. De acordo com Vogler, todas as histórias consistem em alguns elementos estruturais comuns, encontrados universalmente em mitos, contos de fadas, sonhos e, por que não?, em filmes 
também. O guia, portanto, serviu de ferramenta para roteiristas de Hollywood, e tinha por proposta reproduzir 12 estágios da "jornada". Para justificar sua tese, Vogler faz uma lista desses filmes "mitológicos", incluindo alguns dirigidos por Woody Allen. Mas isso não vem ao caso.

O que convém destacar, pois se encaixa no perfil de Blade Runner, são as etapas apresentadas por Vogler. A primeira delas é o "mundo comum". Nele, o heroi aparece em um ambiente costumeiro, que domina e no qual se sente à vontade. Logo depois, vem o "chamado à aventura", que é quando aparece um desafio e algo que perturba a paz interior dele. Com Deckard, isso se verifica no momento em que está no balcáo comendo um prato de massa e, nesse exato instante, aparecem dois policiais intimando-o a falar com o capitão Bryant. No terceiro estágio, há uma recusa ao chamado ou hesitação por medo do desconhecido. O quarto é o encontro com o mentor (o velho sábio, um conselheiro). Na quinta etapa da jornada, Deckard faz a travessia do primeiro limiar, ou seja: compromete-se com o jogo e, a partir de agora, já deixou a rotina para trás. No item seis, aparecem os testes, os aliados e os inimigos. É uma etapa de aprendizado para o heroi.

Continuando a jornada, Deckard se aproxima da caverna oculta (ou do perigo, em outras palavras). No estágio oito, acontece uma provação suprema. Deckard enfrenta a morte e luta contra forças hostis. O nono é o estágio da recompensa e da celebração. O décimo é o caminho de volta, mas no décimo-primeiro há uma ressurreição por ser o teste derradeiro, semelhante ao renascimento do heroi (e, por isso, esse estágio é chamado de "ressurreição"). O décimo-segundo, e último estágio, é o retorno com o elixir, que, no caso de Deckard, poderia ser a própria Rachel. Quer dizer, Rachel seria o elixir de Deckard, porque, conforme sugere o filme, ou o nosso olhar sobre esse final, Deckard e Rachel ficariam juntos, tanto no final da versão para o cinema quanto no da versão do diretor.

Este esquema não é ambíguo. A ambiguidade de que falamos, antes de abrirmos este parênteses, é a relaçáo entre os elementos constitutivos do filme se vistos sob o prisma do imaginário, considerando no imaginário essa constância entre nossa subjetividade e a concretude da vida com que Durand situa a formação de imagens simbólicas na cultura. Por ora, sem entrarmos no mérito do que vem a ser simbolismo para Durand, que, apenas en passant, é diferente do simbólico peirciano, porque, no caso daquele, não existe a ideia de representação, consideramos Blade Runner um filme modelo, mas que, nem por isso, deixa de fomentar uma discussão do imaginário tecnológico. Mas só poderíamos determinar o pertencimento de um imaginário ao regime heroico (enfrentamento belicoso), místico (recolhimento intimista) ou dramático (harmonização) se optássemos pela mitocrítica, que, mesmo sendo de extrema utilidade para a compreensão de lógicas operativas, não é nossa intenção neste artigo.

\section{Entre o instituinte e o instituído}

O filme nos remete a uma orgia, também, porque, contrariamente ao poder instituido, representado pela força policial, o poder instituinte, considerado como a força que emana das pulsóes das personagens, desestabiliza-o. Na linha 
de raciocínio baudrillardiana, a liberação é total. Tudo é liberado, e nesse "tudo" se inclui até o que é "anti" e o que é "crise". Por exemplo: crítica/anticrítica; crescimento/crise de crescimento. Orgia é o que explode. A informação, uma prática do instituído, não preenche o vazio existencial, enquanto a comunicação, a respeito da qual não se tem controle, é mais social do que o social: é hiper-relacional. É a superativação das técnicas do social. Porém, o que fazer após a orgia, já que as finalidades de liberação teriam ficado para trás? Não estaríamos vivendo agora no vácuo? $\mathrm{O}$ que somos realmente? $\mathrm{E}$ se, realmente, formos só uma aparência, sem que no fundo tenhamos de ser algo, além disso mesmo?

Não estaríamos vivendo sob o efeito da simulação? Simulação é repetir o que já aconteceu como se as coisas não tivessem acontecido ainda. É o estado da utopia realizada, e, por isso, já que não podemos realizá-la, passamos a hiper-realizá-las, na visão de Baudrillard, simulando-as indefinidamente. A partir dessa simulação nascem as redes, e, com elas, a proliferação, a contaminação, a saturação, a exaustão, a dispersão e o princípio da incerteza. A metástase (outro termo baudrillardiano) interna no filme é o descontrole da polícia na sua tentativa de manter a ordem. O valor da sociedade em Blade Runner é de caráter fractal (Baudrillard, 2008), porque náo depende mais das categorias próprias que fazem com que se configure em termos de isto ou aquilo. $\mathrm{O}$ fractal - metáfora para o complexo, em Morin - é a metástase interna de que falamos antes, sem nenhuma possibilidade de controle externo. É semelhante ao câncer quando se instala. $\mathrm{O}$ combate é potente, mas nem sempre eficaz.

Em rigor, já nem se poderia falar em valor, por não haver condição de avaliá-lo em termos comparativos, pois cada coisa segue seu próprio rumo, conforme o esquema atual da nossa cultura É como dizer: a ideia de progresso desapareceu, mas o progresso continua. A produção, longe de ter consciência de si, acelera-se, cada vez mais distante de sua finalidade de origem. Desaparece a possibilidade de metáfora, porque não há algo em que esse recurso possa se apoiar devido ao processo de confusão e de contágio. Logo, nenhum discurso poderá ser a metáfora do outro. $\mathrm{Na}$ orgia a que nos remete o filme, vivemos também a ideia do "trans", que significa a falta de uma determinação qualquer, seja de cunho estético, político ou sexual. Na arte, renegou-se o jogo estético em proveito da banalidade das imagens. Uma é geradora da outra. Aos replicantes, inimigos da sociedade pela ótica da polícia, restam o desespero e seu posterior aniquilamento. Nada mais moderno. Nada mais conceitual. Porém, colocada a questão em perspectiva, o termo conceitual estimula a ambiguidade.

Este filme, Blade Runner, é baseado no livro "O caçador de androides", do falecido escritor norte-americano Philip Kindred Dick, publicado no Brasil pela Francisco Alves, em 1989, cujo título original é Do androids dream of electric sheeps? (New York: Ballantine Books, 1968). Talvez mais gente conheça o filme pelo nome do que pelo diretor. Tentando se sentir autor do filme, Scott fez uma segunda versão, chamada The Final cut. É também o nome de um álbum da banda inglesa de rock progressivo Pink Floyd, lançado um ano depois do filme, "Violação de privacidade", filme com Robin Williams, que estreou no Brasil em 2005, e, ainda, um software profissional de edição desenvolvido pela Apple. 
Blade Runner é, curiosamente, um filme de 1982, baseado em um livro de ficção científica escrito em 1968, que foi publicado no Brasil em 1989 e cuja história se passa em 2021, na versão literária, e 2019, na versão cinematográfica. Nesse contexto numérico, o livro de Baudrillard (A transparência do mal), uma das possíveis referências para a discussão do filme, foi, por sua vez, publicado em 1990, no período do colapso da Uniáo Soviética, após a Queda do Muro de Berlim, em 1989, e da popularizaçáo do computador de uso pessoal e da Internet.

Em Blade Runner, ainda, a presença de replicantes inspira medo e angústia, porque não se sabe quem são e onde estão (camuflados, certamente, para que não sejam pegos). $\mathrm{O}$ contraponto aos replicantes seria a polícia, cuja missão é exterminá-los. Vive-se, aqui, na orgia novamente (que também é caos e vácuo). Os replicantes são, na verdade, produto do homem que, agora, deseja descartá-los por receio que se tornem melhores do que o próprio homem que os criou. Porém, os replicantes pareciam desenvolver alguma espécie de desejo (mas precisavam aprender a tê-lo, o que não estava no script). Os replicantes, no fundo, não sabem o que são e o que fazer. São autômatos. Não sabem para onde se dirigir. E vivem, se é que aquilo que vivem pode ser chamado de "vida" pelo modelo tradicional, de maneira errante, nômade, transitória, efêmera. A sua força descomunal náo tem qualquer funcionalidade. Qualquer tentativa de aproximação com os humanos é infrutífera. São individualidades que não aprenderam a viver em grupo.

A ausência de raiz, que se verifica na história de um modo geral, e não apenas no grupo de replicantes, é uma das perdas geradas pela pluralidade do eu (sou muitos "eus", conforme a circunstância) na pós-modernidade. A história questiona, em linhas gerais, o que seremos daqui para frente. Questiona, portanto, a nossa identidade. Uma empresa, a Tyrell Corporation desenvolveu robôs, os replicantes. São meio a meio: máquinas com aspectos humanos. Alguns deles se rebelaram e se misturaram aos seres humanos convencionais na Terra. Os Blade runners são policiais treinados para identificar e executar ("aposentar") um replicante, que recebera um chip programado para ter quatro anos de vida. Quatro deles estavam na Terra, e é por isso que entra em ação o caçador de androides (Harrison Ford). O "eu”, portanto, na perspectiva do filme, não seria, conforme pensa Maffesoli, "uma frágil construção, sem substância própria” (1996, p. 304)?

Vattimo afirma que "a essência do moderno só se torna verdadeiramente visível a partir do momento em que o mecanismo da modernidade se distancia de nós" (1996, p. 102). Acrescenta que o indício desse distanciamento é o esvaziamento do conceito de progresso. Se concordarmos com Vattimo, o esvaziamento do conceito de progresso resulta no esvaziamento, também, do conceito de qualquer política. Esta é desprezada em Blade Runner. A política, portanto, não mais existiria como fenômeno específico, da mesma forma que a arte genuína, representativa do gênio autoral e de uma natureza aurática. Ora, não há mais um original, uma aura e um gênio artístico dotado de inspiração divina. $\mathrm{O}$ que aconteceu na arte é similar ao que ocorre na política. Este abalo na capacidade de transformação social da política se verifica no que poderíamos chamar de niilismo cotidiano, a exemplo do cotidiano de Deckard e Rachel. 
O niilismo não é nem pessimista, nem otimista. Vattimo, ainda, não acredita na morte da arte, mas nela (nessa morte e nessa arte) enquanto chance de abertura para acolher novos sentidos, e que náo precisam ser, necessariamente, negativos, a exemplo da crítica frankfurtiana à suposta transformação da arte em mercadoria. Poderíamos parafrasear Vattimo. Náo precisamos, dessa forma, enterrar a política. Porém, a política de caráter ideológico e de conscientização das massas, como aconteceu na revoluçáo bolchevique de 1917, sucumbiu à espetacularização (ou, para ficarmos com Vattimo, sucumbiu à universalização do domínio da informação). A forma vale mais do que o conteúdo. As promessas caíram no vazio. Percebe-se, agora, que o que se deseja é algo factível neste espaço e neste tempo presentes. O fim das grandes narrativas, inclusive de caráter marxista, é uma comprovação disso. É neste contexto que podemos compreender a pós-modernidade, um ceticismo em relação às interpretaçôes racionalizantes, a relativização dos marcos referenciais e a valorização do conteúdo simbólico.

Em termos sociológicos, poderíamos situar a característica dos personagens no contexto de um presenteísmo, que é o querer viver - como a própria palavra designa - o presente, sem um projeto de vida amarrado ao futuro. Deckard e Rachel, no final aberto de Blade Runner, contentam-se em descer o elevador juntos. E isso já basta. O trágico, outra faceta de Blade Runner, não nos remete a uma soluçáo simplificada. Por que a vontade de viver (ou poder) está diretamente relacionada à morte? A equação é simples: porque se sabemos da nossa morte, temos de aproveitar ou gozar o máximo possível o que o momento (e não o futuro) nos oferece. É isso, precisamente, o trágico pós-moderno que aparece no espírito de Nietzsche e que ele deixa muito claro em "A origem da tragédia" e "A visão dionisíaca do mundo". O autor não faz concessões ao projeto da modernidade. Ele não falava nesses termos, obviamente, porque a noção daquela expressão apareceu depois dele. Porém, toda a obra nos remete ao pensamento trágico.

Poderíamos ver no trágico nietzschiano o comportamento de Dekard e Rachel em Blade Runner. Nesse aspecto, o espiritual e o corporal passariam a coexistir dentro do corpo em estado de constante tensáo, e mais do que isso: uma tensão irreconciliável, como é própria da natureza de todo tensionamento enquanto tensionamento. Nada mais trágico. Nada mais pós-moderno. Nietzsche é o filósofo da pós-modernidade a partir do momento em que anuncia a morte de Deus. Se na modernidade o projeto era seguro e o progresso certo, depois que morre o Senhor de todas as açóes, também se esvazia o sentido das coisas. Acreditar e ter esperança, a partir de Nietzsche, é uma quimera. O interessante é que, nem por isso, vivemos com menos ardor e paixão, como é o caso dos protagonistas do filme em questão. Até pelo contrário: a consciência da morte aumenta a vontade de viver, o que nos dá a noção exata do trágico pós-moderno.

O autor explica que "as regras da sintaxe poética são ditadas pelo gosto, não pelo entendimento" (DUFRENNE, 1969, p. 98). Este aspecto, próprio da Teoria da Informação, tem importância, para nós, porque a opçáo por uma obra autoral também tem a ver com o nosso gosto (traduzido, por 
sua vez, por nossa sensibilidade). O belo, na opinião de Dufrenne, é o que faz sentido. O autoral, também. Em outros termos, "poética é a obra que induz o leitor [espectador] ao estado poético" (Ibid., p. 101). O termo "estado poético" pode ser lido como "emoção", ainda de acordo com Dufrenne. Poesia emociona. É a descoberta, segundo Valéry, citado por Dufrenne, de um mundo singular. Toda obra autoral nos remete a uma singularidade, que é resultante de um espírito imaginativo do seu autor. Este espírito imaginativo tem, dentro de si, um ato de criação livre, para além das injunçôes objetivas do cotidiano. A criação autoral pertence a um tipo de artista, assim como a impressão digital da pessoa. É impossível copiá-la. O motivo é que o autor está concentrado na sua própria natureza poética, e não atento à produção em série de filmes, através das fórmulas de manuais.

Ridley Scott, o diretor de Blade Runner, fez, neste caso, considerando o que se disse anteriormente, uma obra autoral. O artístico, na nossa concepção, se fundamenta na qualidade do que é arte, e não cultura. Produtos culturais são facilmente observáveis. Já os de natureza poético-autoral, não, porque são, conforme Godard, exceção. $\mathrm{O}$ autor se insere no que Dufrenne chama de "o poético no poeta". A diferença entre o ser que cria e o ser que vê é que o primeiro está diante da obra enquanto utopia; o segundo, da obra consumada. O mesmo Dufrenne, em "Estética e filosofia", apresenta alguns caminhos para o entendimento da estética. Um dos pontos que gostaríamos de salientar é o fato de que, segundo ele, a experiência estética diz respeito a uma sensibilidade. "Nós nos confiamos sempre ao veredito da sensibilidade: o criador para julgar a obra acabada; o espectador para julgá-la bela" (DUFRENNE, 2008, p. 90). Entre um e outro, poderíamos acrescentar, existe um segredo, um segredo insondável e intraduzível.

Assim, procuramos estabelecer alguns parâmetros de análise: o imaginário, o cinema, a autoria e a identidade. O imaginário, esse conector de toda atividade humana, que é uma tentativa pulsional de equilíbrio entre nossos desejos e a racionalidade concreta que nos cerca, é o que se dá a ver. Sua presença, em qualquer circunstância da esfera humana, inverte a lógica do dever-ser para aquilo que é. No caso de Blade Runner, consiste na paisagem de um mundo sombrio, niilista e trágico, evidenciado pela fotogenia, a aura de um filme. Cria-se porque se imagina, e não se imagina porque se cria. Toda técnica, inclusive a do cinema, é resultado antes de um imaginário, produto da imaginação.

O imaginário é importante porque resgata uma pluralidade do ser que reúne aspectos relacionados a uma antropofisiologia (a necessidade do devaneio), a uma função de regulação humana diante do incompreensível, como no caso da morte, a uma função de criatividade social e individual (relativizando a percepçáo do real) e a uma função de comunhão social (valorizando o mimetismo e a memória coletiva). A questão da identidade, tanto do filme como filme quanto no interior dele próprio, ou seja, diegeticamente falando, é o ponto nevrálgico da narrativa. O abalo é a incerteza da nossa condição humana. Vemo-nos, pela lente de Ridley Scott, menos ou mais humanos. Escapa-se da antinomia clássica entre o particular e o universal. É como diz 
Maffesoli nesta frase, que poderíamos aplicar a Blade Runner: "ao explodir, e ao fazer tudo explodir, a imagem muda completamente a paisagem intelectual à qual estávamos habituados, donde seu aspecto devastador. Com a imagem tudo é singular" (1995, p. 140-141).

\section{Referências Bibliográficas}

BAUDRILLARD, Jean. A transparência do mal. Ensaio sobre os fenômenos extremos. Campinas: Papirus, 2008

DUFRENNE, MIkel. O poético. Porto Alegre: Globo, 1969.

. Estética e filosofia. São Paulo: Perspectiva, 2008.

DURAND, Gilbert. O imaginário - Ensaio acerca das ciências e da filosofia da imagem. Rio de Janeiro: Difel, 1998.

HEIDEGGER, Martin. Ensaios e conferências. Petrópolis: Vozes, 2008.

LEGROS, P.; MONNEYRON, F.; TACUSSEL, P.; RENARD, J-B. Sociologia do imaginário. Porto Alegre: Sulina, 2007.

MAFFESOLI, Michel. A contemplação do mundo. Porto Alegre: Artes e Ofícios, 1995.

___. No fundo das aparências. Petrópolis, Vozes, 1996.

MORIN, Edgar. O cinema ou o homem imaginário. Lisboa. Relógio D'Água, 1987.

NIETZSCHE, F. A origem da tragédia. Guimarães Editores, 1996.

___. A visão dionisíaca do mundo. São Paulo: Martins Fontes, 2006.

VATTIMO, Gianni. O fim da modernidade. Niilismo e hermenêutica na cultura pós-moderna. Martins Fontes: São Paulo, 1996.

VOGLER, Christopher. A jornada do escritor. Estruturas míticas para contadores de histórias e roteiristas. Rio de Janeiro, Ampersand, 1997.

WUNENBURGER, Jean-Jacques. O imaginário. São Paulo: Edições Loyola, 2007.

\section{Filme:}

BLADE RUNNER $O$ caçador de androides (Edição Especial, DVD Triplo). Ridley Scott. Warner Bros Entertainement Inc. 2009.

\section{Notas}

1. O filme Blade Runner, o caçador de androides, do diretor inglês Ridley Scott, teve quatro versões: a) versão para o cinema, b) versão internacional, c) versão do diretor e d) versão final do diretor. Na primeira delas, os produtores editaram a cópia entregue por Scott, a fim de tornar o filme mais comercial e ameno, acrescentando, entre as principais modificaçóes, a voz-off do personagem de Deckard, interpretado por Harrison Ford, com a voz dele próprio, e outro final para o filme. A segunda é praticamente igual à primeira, Todavia, considerada 
mais violenta. Ambas são de 1982. A terceira versão, de 1992, é a chamada "versão do diretor", com a aprovação dele, mas sem os recursos de edição digital que introduziu na quarta e última versão do filme, de 2007, a que, segundo depoimento do próprio diretor no DVD triplo, lançado no mesmo ano, seria a que mais lhe agrada. "Esta é a minha versão predileta do filme. Foi totalmente restaurada a partir do negativo original. Passou por um moderno processo digital. Supervisionei pessoalmente todo o processo e a nova mixagem de som. Também fiz alguns realces e ajustes ao longo do filme”, diz Ridley Scott. Esta versão final do diretor foi comemorativa dos 25 anos de lançamento do filme, com cópia restaurada e remasterizada digitalmente e algumas cenas estendidas.). 